\title{
HERACLITUS’ DISCURSIVE AUTHORITY
}

\author{
L Jordan (University of Cape Town)
}

\begin{abstract}
Heraclitus, who lived and flourished in Ephesus sometime in the late sixth century, stands quite alone amidst the Presocratics. His thought is expressed in fragments that represent early and beautiful prose artistry, their aphoristic quality matched very rarely. That, combined with a willingness to flout logical doctrine and a seeming ability to adapt to many schools whilst never being fully absorbed by them, has made him a solitary yet immense figure in philosophy. Ultimately, he provided the model for Nietzsche's Zarathustra.

His enigmatic thought has led to many interpretations, which in turn have led to their own important developments in Western philosophy. ${ }^{1}$ On the other hand, his often radical statements have with equal frequency led to his simple dismissal as an eccentric. That dismissal is frequently involved in questions of philosophy's discursive features, a question that is controversial even to frame. ${ }^{2}$ Hence much could be gained from an examination of the discursive features of Heraclitus, and in particular one deceptively simple question: why did his contemporaries take him seriously? To answer this, we must first examine what else they took seriously.
\end{abstract}

\section{Authoritative discourse in oral/literate Greece}

Ionia in the late sixth and early fifth centuries was a culture in transition from predominantly oral to literate forms of discourse. This oral culture looked to the oral body of Homeric verse for its authoritative social discourse, indeed this verse was the prime means of enculturation, or the implanting of socially acceptable behaviour. ${ }^{3}$ In addition, the performance and space of social actions were saturated by epic verse. A key institution for the creation and dissemination of culture, the symposium, was directly linked to the Heroic poems by the inscription of epic verse on pottery, hence re-enforcing the importance of oral paideia for social order. ${ }^{4}$ This practice continued in the fifth and sixth centuries, albeit in a diminished form, with the emphasis laid on identification with heroic personages, and the expression of a way of life. ${ }^{5}$ Similarly, in the ritual sphere, dedicatory objects were inscribed with composite hexameters. Three features of this practice are of great importance: the inscriptions were a form of non-perishing, continuous communication with the god in his own home, the inscriptions were for the god to read, not humans, and the inscribed dedication was connected with the whole ritual oral performance, a performance of primary importance in public discourse. ${ }^{6}$

In the public employment of religion, rooted in the various oracles, we find a more complex intersection between authoritative oral utterance and developing methods of

1. Kahn (1979:3-6) gives a very useful survey of the later influence of Heraclitus on antiquity. Amongst moderns the great names are of course Nietzsche and Heidegger.

2. See Most's (1999b:332-333) discussion, especially Aristotle's formative influence.

3. Robb (1994:174).

4. Robb (1994:52).

5. Robb (1994:63).

6. Robb (1994:56, 59, 61). The last feature is an interesting indication of the continuous transition between orality and literacy. 
inscription. First of all, it is necessary for us to distinguish between the oracle as day to day, historical reality, and as legendary predictor. ${ }^{7}$ The historical oracle had no marked preference for discursive form, dispensing sanction orally that could be written down, with no clear preference for such inscription. ${ }^{8}$ On the other hand, the legendary oracles were clearly stamped as oral performances, which were spoken to questioners, and yet their transmission and position as authority was dependent on the tradition that invented and made use of them. Hence they were discursively bound to precisely the forms highlighted above as that tradition moved from orality to literacy. Within that tradition, though, certain features stamp them, so that they form a sub-discourse. However, the historical utterances in a sense derive their authority from the prestige of legend, and are rather ordinary, so that we shall cease to consider them.

By the period of Heraclitus' activity legal procedure was similarly involved in a transition from oral to literate authority. A legal dispute would be arbitrated in two distinct phases. In the first, a case was decided in strict, automatic accordance with a written code, but only on the basis of the oral testimony of procedural witnesses, ${ }^{9}$ who served to verify the performance of a specific event, i.e. as the oral equivalent of written records. These witnesses served to legalize social actions, especially regarding the distribution of property, and, indeed, were the only admissable form of record, so that their veracity was unquestionable. ${ }^{10}$ Hence early literate law was fully dependant on oral witnesses, and if these witnesses did not perform their duty societal breakdown would ensue. In this period of Greek life we have a picture of judicial authority resulting from the combination of inscribed law and oral performance.

The forms of authority in paideia, religion and justice contemporary with Heraclitus are then based on an intersection of inscribed text and oral performance. Turning to the discourse of this authority we find that it is imbued with by the major epic poets, Homer and Hesiod. The inscriptions on objects involved in social performance are all taken from the body of epic verse, which served to constrain societal behaviour. ${ }^{11}$ More importantly, the features of this verse served to constrain, perhaps constitute, succesful public discourse through the seventh to fourth centuries. ${ }^{12}$ These crucial features were a claim to truthfulness, ${ }^{13}$ to a content of utmost importance, by a range of signification outside the discourse's formal limits, a requirement of narrative, and a greater concern for formally small elements than larger ones. ${ }^{14}$ In addition, for a discourse to reach its audience it was necessary for that discourse to adopt many of the linguistic features of Homer and Hesiod. ${ }^{15}$

Legendary oracular utterance requires two central features. First, it is necessary for the prediction to be of utmost importance, especially for a heroic character, in order for it to be

7. As Fontenrose (1978:34) shows, the historical oracle chiefly pronounced prosaic sanctions, completely different from those of legend and legendary history, especially Herodotus.

8. Parke and Wormell (1956:33).

9. Robb (1991:648).

10. If two witnesses contradicted each other the trial went to a further stage where the judge adjucated between competing claims. However prevalent false witnessing, for the sake of judicial performance all witnesses had to be admitted as valid (Robb 1991:649-650).

11. Robb (1994:53).

12. Most (1999b:334).

13. I am not aware of any thorough study on the nature of epic "truth". This truth is guaranteed by divine sanction, but can we say that they are identical?

14. Admirably developed by Most (1999b:343-350), who points out early Greek philosophy's later conformance to these features. Naturally, Heraclitus' specific conformance is discussed below.

15. Eloquently argued by Most (1999b:336). 
handed down as traditional. ${ }^{16}$ Second, they have two distinct sets of features, each corresponding to a particular temporal view. In hindsight, they are clear yet ambiguous, their initial meaning revealed from later events. ${ }^{17}$ Further, seen from this angle their meaning is dependant on a narrative which later validates their prediction. On the other hand, they are frequently embedded in narrative frameworks which require the imaginative act of hearing them for the first time (ad tempo), at which point the ambiguity need not be declared, and, importantly, narrative is not of crucial importance, and the utterances stand on their own as divine truth. Such discursive shifting is quite remarkable, and allows a wide range of identification.

As for witnessing, the crucial features are the necessity of physical proximity to an action in order to authoritatively describe it, and the formal requirement of oath-taking at both stages of the act, that is before both recording it and manifesting it by oral performance in court. ${ }^{18}$ In addition, epic discourse again intrudes into other forms of authority, since it was commonplace for epical formulas to be quoted in disputation. ${ }^{19}$

Finally, we move to the linguistic features of this oral discourse. For both epic and religious utterance we first note the crucial use of ambiguity. In oral societies polysemic word use and word play is always common, ${ }^{20}$ but in archaic and classical Greece it was especially prevalent. It was prominent in Homer, ${ }^{21}$ though, interestingly, Hesiod used it infrequently, and seemed wary of it. ${ }^{22}$ On the other hand, it was prevalent in legendary oracular utterance which foretold future events. Such ambiguity not only masked intent (and provided pleasing storytelling devices), ${ }^{23}$ but served as the only fit vehicle for divine utterance. As defenders of the oracle pointed out, divine speech could not be rendered simply and intelligibly in human terms. ${ }^{24}$ Polysemic word-play is hence rooted in the divine, where it served to convey multiple meanings within a single utterance. The device seems necessary in the absence of written texts within which to elaborate difficult concepts. In societal performances, though, in which utterances relate to human experience, precisely a specificity of meaning is required. Ambiguity in a procedural witness obviously would be judicially calamitous, and in plainly didactic verse the need for precise instructions is equally clear. ${ }^{25}$ Similarly, ambiguity is entirely absent from the historical oracles of Delphi, which are predominantly plainly expressed sanctions of courses of action. ${ }^{26}$ We can tentatively posit that precisely ambiguity in language served to identify authoritative discourse with the divine and the heroic, and with the expectations of divinity and oracular utterance, and, indeed, as an indication such discourse was inspired.

16. Fontenrose (1978:32), who shows that most legendary responses were "dramatic" commands of a personal nature, often connected with life and death. Importantly, they were given to heroes, and preserved in the tradition of colonization.

17. See Kahn (1979:91), to which we should add that it is precisely this resolution of meaning that tells us the statement was polyvalent in the first place.

18. Robb (1991:643).

19. Robb (1994:78).

20. Robb (1994:47).

21. Stanford (1972:114).

22. Stanford (1972:116).

23. Fontenrose (1978:234).

24. Stanford (1972:121).

25. Hence Hesiod's warning against ambiguity (Stanford 1972:160).

26. Frequently cultic practices (Fontenrose 1978:32). 
Finally, we can elicit two very subtle features of oral discourse. On a constitutive level, oral discourse presupposes that its participants share a common language. Without the infinite repetition of inscribed text, and hence the possibility of being deciphered, an oral act is meaningless if it is not immediately understood. ${ }^{27}$ Hence authority in oral discourse requires participants who have a common referential code. On a formal level we should note that for its effectiveness oral discourse requires a heightened efficiency of language. Without a text which by repeated reading may clarify or enrich each statement, to be effective an oral performance must display itself all at once. This does not require every feature to be instantly accessible, but precisely that the presence of each feature must announce itself. ${ }^{28}$ Ambiguity is a direct consequence of this principle; in Greece it results in concentrated expression, as found in the Homeric similes and formulas, and the elaborate ritual practice surrounding oracular utterance. Similarly, didactic poetry, or formal witnessing, would be clearly unambiguous, and reinforced by the swearing of divine oath. ${ }^{29}$

\section{Heraclitus'discourse}

Turning to Heraclitus' discourse we must first pay attention to its structual form, i.e. the means and conditions of its performance and transmission. Here we must tread carefully, relying on the doxographic material and our understanding of the prevailing cultural institutions. My method will be to accept as valid any part of the tradition unassailed by reasonable doubt.

First, it is almost certain that Heraclitus himself wrote a book of some sort. ${ }^{30}$ On the other hand, it is equally clear that during his lifetime the contents of that book would have been almost solely accessible through oral performance, ${ }^{31}$ and this content was of the aphoristic form we possess today. Hence we have an inscribed text whose small, self-contained units are capable of effective oral performance, but written in prose (if rhythmic) and not forming a coherent narrative. These latter features bring the work closer in its structural aspects to the law code and the ad tempo oracle than the epic poet. ${ }^{32}$ As a performance, then, it does not derive its authority from a paideutic function reliant on the narrative exemplum, but rather on

27. Though as a caveat we should note that an oral act will clearly produce some effect on the speaker even if it is comprehended but misunderstood.

28. In other words, we cannot elicit linguistic features from oracular texts by repeated readings. Frost's repetition of the line "and miles to go before I sleep”, at the end of Stopping by Woods on a Snowy Evening, restores this quality of obvious metaphor to a literate text.

29. Two interesting and important questions are raised from this discussion. First, what is the role of lyric poetry, and what are its authoritative features? Second, how does writing affect ambiguity? Answers to these questions, especially the latter, are suggested in this paper, but a more thorough study would be immensely valuable.

30. Tejera (1991:155) objects that it is only referred to as a $\sigma 0 ́ \gamma \gamma \rho \alpha \mu \mu \alpha$, which does not necessarily imply a “book”, and that at his time Heraclitus' would have been unlikely to write one. However, only 50 years later Thucydides calls his book a $\sigma u ́ \gamma \gamma \rho \alpha \mu \mu \alpha$, and already at the time the Ionian prose authors were writing books referred to as their $\lambda$ ó

31. Even if Heraclitus were placed later than the Apollodoran dating of 480 BC, which is most unlikely (Kirk, Raven and Schofield 1983:182), the discursive forms of his society would remain primarily oral. Indeed, they only begin to change in Athens in the late fifth century BC (Robb 1994:especially ch. 58).

32. A feature starkly revealed by even a superficial comparison to Xenophanes, Parmenides and Empedocles, all of whom composed in verse, heavily invoking epic themes (Most 1999b:351-353). 
the commanding order of the law code and the ad tempo oracular utterance, which we remember is sanctioned by divine infallibility. ${ }^{33}$

An important subquestion involves the societal context of the book's performance. It might seem strange to speak of Heraclitus' societal performance given his traditional isolation, but the rapid dissemination of his influence, ${ }^{34}$ and the exclusively performative means of dissemination, show that his writings must have been socially performed.

Moving from the overall performative aspect of Heraclitus' discourse to the more specific linguistic form we discover an astonishingly varied use of the differing authoritative discourses sketched above. Fragment DK 22 B1, which I give in full below, even if it were not the first part of the book, ${ }^{35}$ is by far the longest continuous text we possess, and is stylistically highly representative of the rest of the fragments. Hence I shall attempt to elicit precisely those stylistic features from this fragment, hoping thereby to demonstrate the use Heraclitus makes of his surrounding authoritative discourse.

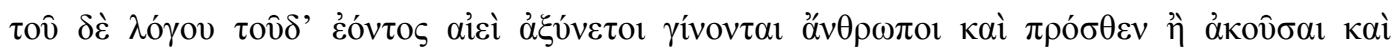

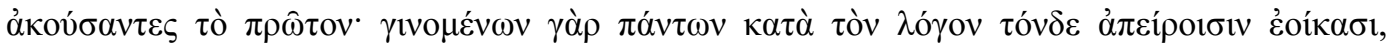

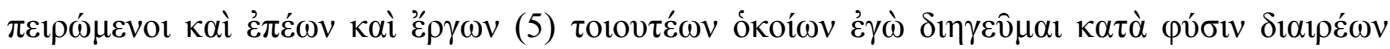

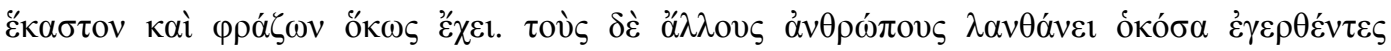

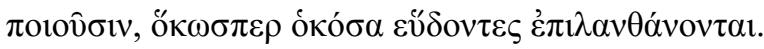

This word existing forever men do not comprehend both before they hear it and having heard before; for all things occurring in accordance with this word, they seem as the inexperienced, experiencing words and deeds such as I reveal, distinguishing each and saying how they are; but other men are eluded by what they do being awake just as what they do being asleep escapes them. (DK 22 B1)

The first sentence of this fragment makes a series of claims both explicit and implicit. First, I take the adverb aicí as a praegnans constructio modifying both of the first two clauses. ${ }^{36}$ The

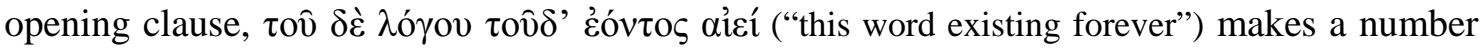
of bold claims resting on the various associations of $\lambda$ ó $\gamma$ os. As Kahn (1979:97) notes, it evokes the standard opening of empirical prose works, notably that of Hecataeus, who indeed

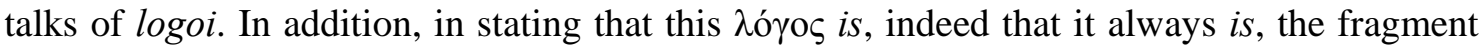
asserts both itself and its content in the terms of epic epistemology, as a primarily existent

33. If we accept the story that Heraclitus dedicated his book in the temple then we can posit immediately that he is invoking both epic and divine authority, since then his book becomes an offering which speaks to the god. However, the conclusions one could draw from the anecdote are out of all scale to its veridity, so I will not consider it in the main discussion.

34. Diogenes Laetius IX, 5. The rapidity and extent of his dissemination is evinced by the presence of a Heraclitean, Cratylus, in late fifth century BC Athens (Kahn 1979:3).

35. Tejera (1991:493-494) points to the lack of consensus on the issue, but as Kahn (1979:7, 967) points out, the fragment is quite unique for length and syntactic complexity. We should note that the fragment is exclusively methodical, simply outlining the problems of performance, without any explicit philosophic content. Finally, no one has yet provided a good reason to doubt the veracity of Aristotle when he says the fragment came at the beginning of the writing.

36. In performance the first two clauses form a perfect isocola if aicí is spoken as part of the first clause, so that at least in speaking it more naturally applies to the first rather than the second clause. After Kahn (1979:93), most scholars have taken aisí as part of the first fragment (e.g. Curd 1991; Robinson 1991), yet I see no reason for excluding both except for a bizarre requirement for a clarity obviously not present in the remainder of the fragments. 
object. It also conforms to the expectation of comprehensiveness by declaring that it holds forever, a claim also resonant of the "infinite" and "unperishing" substances of the Milesians.

On the other hand, as it claims these discursive forms it modifies them by expressly omitting any claims to authorship. The $\lambda$ ó $\gamma$ o $\varsigma$ simply is, it has not been written (as Hecataeus), nor has it been inspired (as epic). Indeed, the first eight clauses of the fragment are exclusively concerned with the interaction of the $\lambda$ ó $\delta \varsigma$ and the audience, those who hear or attempt it. Indeed, when the author is finally introduced, he is related to the hearers and the

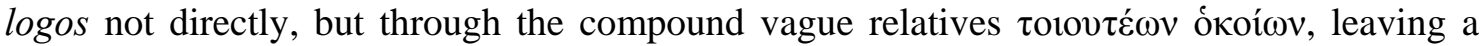
deliberate seperation between "what sort of things" are investigated, and the logos with its hearers. The concern with impersonality here is remarkable, and requires some explanation. I suggest, tentatively, that this erasure of the author, in an oral context, implicitly gives the text the status of a law code, in which laws (short, non-narrative texts) are inscribed as a nameless authority, common to all, to be experienced in a court. A number of clues in the text point in

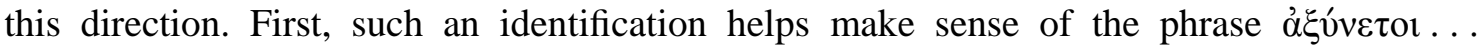

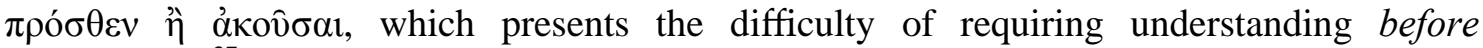
performance, ${ }^{37}$ if we remember the judicial principle that ignorance does not excuse violation, i.e. that one must understand the law before formally hearing it in a "trial". In

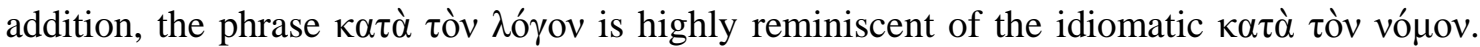
We may also note the suggestive emphasis on the oral act and the necessity of experience, both aspects intrinsic to oral legal authority.

As interpretatively rich as this suggestion is, we cannot consider it either exclusive or solid enough to serve as a base for an extensive examination of the fragments. In particular, the opening fragment is also tied to esotericism and the ambiguity of oracular utterance. A certain tension in meaning and syntax mark the entire fragment, beginning with the syntactical position of aicí. First, the fragment states that men "become inexperienced", and

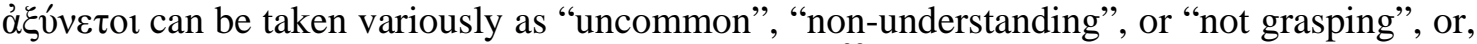
in Homeric terms, as a very physical non-perception. ${ }^{38}$ Words are repeated in differing forms and different positions, such as the chiasma in the first sentence on $\pi \rho o ́ \sigma \theta \varepsilon v / \alpha \dot{\alpha} \kappa o v \sigma \alpha \nu \tau \varepsilon \varsigma-$

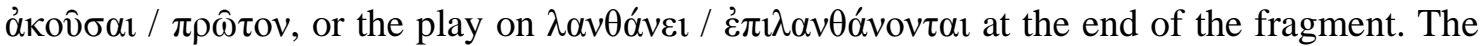
rhythm of the prose frequently approximates verse in balance and regularity, and sound devices link opposites together. Such prose is highly reminiscent of the stylized, deliberately ambiguous verse of the legendary oracle, although the wide discursive ambiguity preclude any firm conclusions but an attempt towards an esoterism reminiscent of the way oracles function in legend. ${ }^{39}$

If we consider the content of Heraclitus' fragments we find the same pattern of discursive incorporation and modulation. First, we must note the use of epic figures, beginning with кai

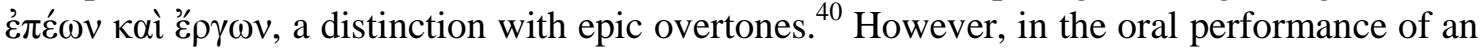
inscribed text words and works are completely coextensive, as in performance work becomes

37. Kahn (1979:98).

38. Lesher (1983:165). The word is a key term in the Homeric idea of perception, clearly corresponding to what Mourelatos (1973) calls the naive metaphysics of things. Its use here in the negative and so close to "hearing" implicitly shifts away from just such a metaphysical view.

39. A veiled identification made rather more explicit in DK 22 B93, on the Lord of Delphi who "indicates", commonly taken as a selfreference to Heraclitus' own difficulty. Fontenrose's (1978:238) suggestion that the fragment merely indicates that the Pythia is the sign for Apollo's speech is absurdly banal.

40. Kahn (1979:99). 
word, not, as in epic, referring to spheres of action and counsel. ${ }^{41}$ Further, we find in a few other fragments direct reference to previously authoritative figures themselves, though not in the exclusively derisive terms generally assumed. Several fragments are clearly agonistic, none more so than DK 22 B42 and A23, both again given below, in which Heraclitus states that Homer and Archilochus should be expelled from the contests, and that poets are untrustworthy.

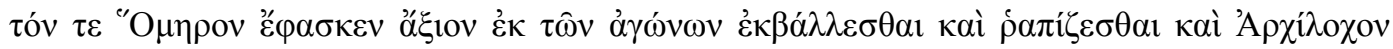
ónoíws.

Homer deserves to be thrown out of the competition and beaten with a staff, ${ }^{42}$ and the same goes for Archilochus. (B42)

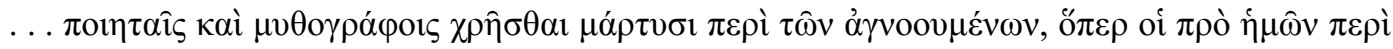

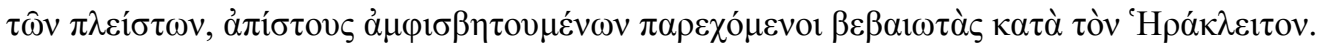

... Using the poets and mythmakers as witnesses about the unknown, ..., they are bringing in untrustworthy authorities for the dispute, according to Heraclitus. (A23)

Both, however, simultaneously affirm the previous position of the poets, ${ }^{43}$ and elicit the question: who is to replace them? ${ }^{44}$ Similarly, Hesiod, who is $\delta 1 \delta \alpha ́ \sigma \kappa \alpha \lambda \circ \varsigma \delta \varepsilon$ $22 \mathrm{~B} 57)$, is untenable as he does not know day or night. Those who have $\pi$ o $\lambda v \mu \alpha \theta$ í $\eta$ will also not do, since they have not been taught understanding. ${ }^{45}$ We should not be quick to assume that authority is being claimed for investigation, for precisely Pythagoras, despite having investigated greatly, is impugned for bad techne, choosing what he wanted, and making his own wisdom (DK 22 B129). ${ }^{46}$ It is also curious that nowhere in the fragments are the philosophers of the Milesian school mentioned, so that without preconception it seems Heraclitus does not consider himself as competing with them. ${ }^{47}$ On the other hand, a number of the features pointed out in this paper indicate some continuity with the Ionian prose

41. This unity of word and deed in performance was perhaps noticed and so commented on by Heraclitus as an implicit and highly interesting example of the unity of opposites.

42. There is a pun in the Greek here that I have not yet seen adequately translated, and is certainly beyond me. The pun is on $\rho \alpha \pi i$ i $\varepsilon \sigma \theta \alpha$, to be beaten with a staff, with $\rho \alpha \psi \omega \delta \varepsilon \hat{\imath} v$, to recite of epic.

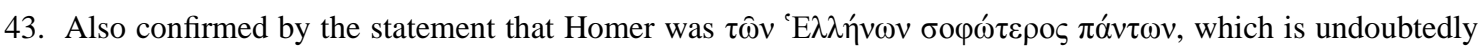
ironic, but on first hearing, to a contemporary, would have been merely an affirmation of an already held position. Homer is not merely derided (Most 1999b:338), but instead the fragment points out that men can be deceived because of a lack of sight, i.e. the causes of deception are frequently hidden from us (on which see Lesher 1983:158).

44. Analogous, but perhaps more extensive, to Xenophanes' use of the poetic form and attack on the epic poets so as to compete himself in rhapsodic competition (Most 1999b:352).

45. Lesher (1983:1578) points out that here noon and its acquisition are analogous to linguistic comprehension, though how one is taught language, and what Heraclitus thought of linguistic acquisition is an unpursued question.

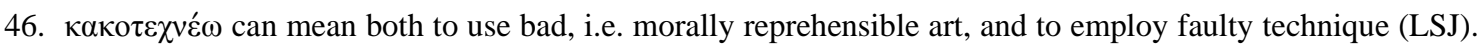

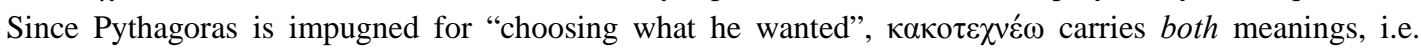
Pythagoras' fault lies in creating a faulty system after his inquiries, and hence is "worthless”. Such a line of reasoning prefigures Ralph Ellison's statement that bad craft is a moral wrong.

47. The reference to Thales in DK 22B 105 is uninformative, seeming a mere restatement of the tradition surrounding Thales (Kahn 1979:113). 
tradition, so that we cannot altogether rule out a connection, but we can posit that if it exists such a connection is not of great significance. ${ }^{48}$

None of these fragments tells us to which authority we should turn having rejected earlier fragments. ${ }^{49}$ Indeed, no such explicit statement is given in any fragment, and certain hints contradict each other, resulting in the tangled modern attempts to extract a systematic epistemology from Heraclitus. ${ }^{50}$ Perhaps the largest obstacle in this problem is our greatest clue, since Heraclitus exonerates even himself from authority, positing instead that one should listen to the logos. Explosive as it seems, the fragment is in fact superfluous, for the placement of the text itself as the authoritative discourse is implicit everywhere. As discursive space is cleared precisely the discourse that clears it fills that space, providing that this discourse bears the structural and formal characteristics of pre-existing authority. On the other hand, if we examine the internal qualities of Heraclitus' $\lambda$ ó $\gamma$ os, and allow ourselves some speculation, we note that contemporary consensus holds it as referring both to Heraclitus' discourse and the object of that discourse. ${ }^{51}$ Hence, by performing the steps of distancing himself from his discourse, and so making it self-sufficient, and simultaneously of rendering that discourse authoritative, Heraclitus in fact makes of the logos a criterion of objective truth and authoritative utterance. For supremely eloquent evidence of his success in this project we need turn no further than the first words of the Gospel of John. ${ }^{52}$

\section{Conclusion}

The overriding impression gathered from this investigation is that the history of philosophy remains far more complicated than commonly assumed. We may not interpret successive figures' thought without considering the form in which that thought was uttered, ${ }^{53}$ and the consequent interaction of thought and form. Since Plato scholars have assumed philosophic form to be timeless, a constant result of philosophy's eternal truths. Though such an assumption has today largely fallen away, there has been little revision of attitudes towards the pre-Platonists. ${ }^{54}$ This paper has aimed at such a revision in the treatment of Heraclitus, demonstrating that in order to gain a necessary cultural authority he had to adopt forms quite different from modern philosophic discourse, yet powerful enough to remain relevant even

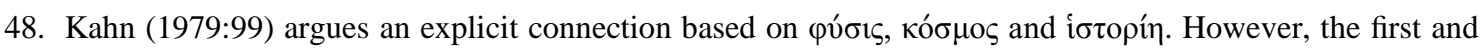
second are not exclusively related to Ionian physics, and the use of the third is by Heraclitus himself given a much wider application (viz. his use of it in describing Pythagoras). Kahn's own arguments against the "natural philosopher" interpretations of Heraclitus contradict his position here.

49. Even in an oral performance, to accept the rejection of an earlier authority is to accept one utterance, not to accept all of them.

50. Amongst others, see the entirely arbitrary attempt of Hussey (1982), the projection of Plato onto Heraclitus in Robinson (1991), and Robb’s (1991) attempt to deny any hint of an epistemology on the basis of a very selective reading.

51. For example, Kahn (1979), Curd (1991) and Robinson (1991).

52. Of course, to reach the Christians $\lambda$ ó $\gamma$ os had to pass through the influence of Plato and the Stoics, but it is precisely this ability to remain vital despite such competing claims that demonstrates the resilience of the logos-concept, even until today when Mourelatos (1973) speaks of a logos-structured world.

53. Tejera (1991:494).

54. Plato is extensively treated by postmodernism, especially Derrida (Waugh 1991:610). I believe that one of Plato's other great deceptions was to convince posterity that his discourse was radically divergent, and that we must investigate how philosophic form travelled from Homer to Plato if we are to understand the discursive crisis in which philosophy finds itself today. 
today. Along the way we have found a Heraclitus even more subtle than we had thought, especially in his attitude towards religion and what one might call the "establishment".

If towards the end of the paper my arguments become more circumstantial, yet even then they retain a perspective lacking in those who cling to an image of philosophy as a radical break with religion. What is clear is that a voice which does not incorporate the discursive features of prevailing authority will quickly be forgotten. Were Heraclitus the conceited figure often presented by current scholarship one highly doubts his book would ever have been performed. This is not to label him popular, far from it, but simply to point out that his discourse, far from an attack on prevailing authority, was in some sense an attempt to join it.

Finally, what only Aristotle doubts, the remains of Heraclitus' writings contain much that is radical, contentious, and profound. Perhaps his most lasting contribution, the grasp of the structural unity of opposites, ${ }^{55}$ was through the texture of his language used to supersede the

ritual religion of Greek society. ${ }^{56}$ Precisely this achievement, to weld philosophy to a form inclusive enough still to be relevant, ${ }^{57}$ places him on one of the peaks of philosophy.

\section{BIBLIOGRAPHY}

Adomenas, M 1999. Heraclitus on religion. Phronesis 44:87-113.

Curd, P K 1991. Knowledge and unity in Heraclitus. Monist 74:531-549.

Fontenrose, J 1978. The Delphic oracle: Its responses and operations. Berkeley: University of California Press.

Hussey, E 1982. Epistemology and meaning in Heraclitus. In Schofield, M \& Nussbaum, M (eds), Language and logos: Studies in Ancient Greek philosophy presented to G.E.L. Owen, 33-59. Cambridge/New York: Cambridge University Press.

Kahn, C H 1979. The art and thought of Heraclitus. Cambridge: Cambridge University Press.

Kirk, G, Raven, J \& Schofield, M 1983. The Presocratic Philosophers: A critical history with a selection of texts $\left(2^{\text {nd }}\right.$ ed). Cambridge: Cambridge University Press.

Lesher, T 1983. Heraclitus' epistemological vocabulary. Hermes 111:155-170.

Most, G W 1999a. From Logos to Mythos? In Buxton, R (ed.), From myth to reason?: Studies in the development of Greek thought, 25-47. Oxford: Clarendon Press.

Most, G W 1999b. The poetics of early Greek philosophy. In Long, A (ed.), The Cambridge companion to early Greek philosophy, 332-362. Cambridge: Cambridge University Press.

Mourelatos, A P 1973. Heraclitus, Parmenides and the naive metaphysics of things. In Lee, E, Mourelatos, A Rorty, R (eds), Exegesis and argument: Studies in Greek philosophy presented to Gregory Vlastos, 16-48. Assen: Van Gorcum.

Parke, H \& Wormell, D 1956. The Delphic oracle, Volume I. Oxford: Basil Blackwell.

Robb, K 1991. The witness in Heraclitus and in early Greek law. Monist 74:638-676.

Robb, K 1994. Literacy and paideia in ancient Greece. Oxford: Oxford University Press.

Robinson, T M 1991. Heraclitus and Plato on the language of the real. Monist 74:481-490.

55. Considered by Mourelatos (1973) as a crucial stage on the way to Plato's epistemology. Whatever one thinks of this language-oriented thought, it clearly set the course for future Western philosophy, and so must be considered decisive.

56. Adomenas (1999) convincingly argues that far from being hostile towards traditional religion, Heraclitus rehabilitates ritual within the framework of an opposition between low ritual and higher truth that is in fact unified. Such a rehabilitation is an astonishing linguistic and philosophical achievement, especially at the same time as narrow rationalism in Xenophanes and Socrates was blighting the higher meaning of traditional religion, a position soon to be encapsulated in Aristotle and accepted until the $18^{\text {th }}$ century. See Most (1999a).

57. Kahn (1979:ix) states that he is "the only preSocratic philosopher whose thought is of more than historical interest today”, and we need only look at his massive influence on Nietzsche and Heidegger, and in turn on the postmodern movement (Waugh 1991:608), to see how enduring is his thought. 
Stanford, W 1972. Ambiguity in Greek literature: Studies in theory and practice. New York: Johnson Reprint Corp.

Tejera, V 1991. Listening to Heraclitus. Monist 74:491-516.

Waugh, J B 1991. Heraclitus: The postmodern presocratic? Monist 74:605-623. 